\title{
EL CLIMA LABORAL Y LA SATISFACCIÓN DE LOS COLABORADORES DEL INSTITUTO NACIONAL MATERNO PERINATAL
}

THE WORK ENVIRONMENT AND SATISFACTION OF EMPLOYEES OF THE NATIONAL INSTITUTE MATERNAL PERINATAL

\author{
Pedro L. Tito Huamaní \\ pedrotito18@hotmail.com
}

Andrea R. Arauz Chavez ${ }^{\text {*** }}$

andrea.arauz@uleam.edu.ec

[RECEPCIÓN: AGOSTO 2015 / CONFORMIDAD: NOVIEMBRE 2015]

\section{RESUMEN}

La presente investigación se realizó en el Instituto Nacional Materno Perinatal (INMP), donde los miembros de la alta dirección tuvieron un papel preponderante para la realización del trabajo de campo. Se planteó como objetivo general de investigación la de averiguar y estimar el nivel de percepción de la cultura y clima organizacional entre los trabajadores del INMP; y como objetivo específico el diferenciar los niveles de percepción de clima y cultura según áreas y grupos ocupacionales, así como identificar los elementos de liderazgo, innovación, recompensa, confort, toma de decisiones, comunicación, remuneración, identidad, conflicto y cooperación, motivación, influyen en la determinación de la cultura y clima laboral.

En el trabajo de campo se aplicó una encuesta ad hoc a los trabajadores y profesionales de la institución. Dicha encuesta fue complementada con entrevistas a profundidad, realizadas entre los directivos quienes, en la mayoría de los casos, corroboraron los resultados obtenidos a través de esas encuestas.

Los resultados son altamente alentadores, por cuanto se pudo comprobar las hipótesis planteadas y éstas tienen, que ver con el comportamiento de los jefes, la mejora de las comunicación, la reciprocidad entre compañeros de trabajo; aspectos que sí configuran un determinado clima laboral, que su vez retroalimenta a la cultura del Instituto Especializado Materno Perinatal.

Palabras clave: Clima laboral, satisfacción laboral, motivación laboral, Instituto Materno Perinatal.

* Doctor en Ciencias Administrativas (UNMSM), Magíster en Gestión Empresarial y Licenciado en Administración (UNMSM). Director del Instituto de Investigación de la Facultad de Ciencias Administrativas (FCA). Docente Asociado de la Facultad de Ciencias Administrativas (UNMSM). Docente de posgrado de la UNMSM y docente invitado en las diferentes universidades del país y el extranjero. Miembro del Directorio de Investigadores del CONCYTEC-Perú.

*** Estudiante del Doctorado en Ciencias Administrativas (UNMSM). Magíster en Dirección Estratégica de Marketing y Ventas (Universidad Viña del Mar, Chile). Docente principal de la Universidad Laica Eloy Alfaro de Manabí (Ecuador). 
This research was conducted at the National Institute Maternal Perinatal (INMP), where members of senior management played a major role in providing for the completion of fieldwork. This general objective research to ascertain and assess the level of perception of organizational culture and climate between INMP workers; and as specific objectives to differentiate the levels of perception of climate and culture as areas and occupational groups. In the same way as the elements of leadership, innovation, reward, comfort, decision making, communication, payment, identity, conflict and cooperation, motivation, influence the determination of culture and working environment.

In a survey fieldwork had doc workers and professionals institution applies. The survey was supplemented with in-depth interviews aimed at managers, who in most cases corroborated the results obtained through the surveys.

The results are highly encouraging, because it could test hypotheses raised and these have to do with the behavior of the leaders, improving communication, reciprocity between co-workers; other aspects that make up a particular work environment, which in turn feeds back to culture Specialized Maternal Perinatal Institute.

Keywords: Working environment, job satisfaction, motivation, Labor Maternal Perinatal Institute.

\section{PLANTEAMIENTO DEL ESTUDIO}

La modernización del Estado es una necesidad en la cual todos los sectores sociales y políticos están de acuerdo, ello implica la actualización de la gestión de cada una de las instituciones públicas, instaurado avances en materia de modernización y profesionalización en la administración del Estado.

Es así como una de las instituciones del sector salud, el Instituto Nacional Materno Perinatal (INMP), se encuentra en un proceso de cambio profundo para adaptarse a las exigencias del mundo moderno, lo que ha llevado a insertarse en la senda de la modernización, que incluye entre otras, la reforma de salud, teniendo como objetivo central la satisfacción de las necesidades de los pacientes, con eficacia, calidad y oportunidad.

Un hospital puede ser definido como una organización, con un espacio estructurado de prácticas, con división y coordinación del trabajo, a través de las cuales se establecen relaciones entre el personal del hospital y un espacio de prácticas médicas; esto es, una estructura de prácticas a través de las cuales el personal especializado se relaciona con personas enfermas o personas con problemas de salud.

El clima organizacional y la satisfacción laboral son relevantes en el comportamiento del personal que labora en cualquier organización; esto "[...] potencia aspectos como la eficacia, diferenciación, innovación y adaptación” (Valle, 1995). La presente investigación pretende despertar la reflexión de los directivos del INMP sobre las condiciones laborales y la forma cómo se desenvuelve el personal, considerando que estos factores son determinantes en el éxito del trabajo de toda organización. Según opiniones académicas, se deben iniciar programas y acciones que cambien los elementos culturales que impiden al personal identificarse con la institución y desarrolle un clima de trabajo altamente motivador, además de lograr niveles de satisfacción personal de acuerdo con tales resultados.

El clima organizacional y la satisfacción laboral son dos variables del comportamiento organizacional que, al establecer una relación entre ellas, nos permiten observar y determinar la relación causal. Por ejemplo, una definición de clima organizacional que nos parece completa es la formada por los aportes de los investigadores Rousseau (1988), y Schneider y Reichers (1990): clima son las descripciones individuales del marco social o contextual del cual forma parte la persona, son percepciones compartidas de políticas, prácticas y procedimientos organizacionales, tanto formales como informales.

La definición de satisfacción laboral que nos parece apropiada es la proporcionada por Bravo, Peiró y Rodríguez (1996), quienes la definen como una actitud o conjunto de actitudes desarrolladas por la persona hacia su situación de trabajo, actitudes que pueden ir referidas hacia el trabajo en general o hacia facetas específicas del mismo. Así, la satisfacción laboral es, básicamente, un concepto globalizador que hace referencia a las 
actitudes de las personas, en diversos aspectos de su trabajo. Por consiguiente, hablar de satisfacción laboral implica hablar de actitudes.

\section{JUSTIFICACIÓN DE LA INVESTIGACIÓN}

Busca mostrar al clima organizacional y la satisfacción laboral como dos variables importantes en el desarrollo de las actividades laborales en el INMP. La encuesta del clima organizacional y la satisfacción laboral tiene por finalidad identificar las mejoras en las áreas de trabajo, viéndolas éstas como oportunidades que favorecen no solo al INMP, sino también al bienestar emocional de sus colaboradores quienes son los encargados de velar por el buen desempeño de la organización. Con esta investigación pretendemos identificar aquellos problemas que requieren solución, identificar carencias, ineficacias y estrategias motivadoras; en suma, saber cuáles son los puntos fuertes y débiles de la organización a juicio de sus protagonistas principales, quienes día a día con su trabajo crean valor en el INMP.

Para el logro de los objetivos propuestos, en la fase de operatividad de la investigación, fue necesario utilizar métodos y modelos matemáticos y estadísticos, especialmente en el trabajo de campo. Para determinar el tamaño de nuestra muestra, además de definir e identificar al trabajador al ser encuestado empleamos formulas estadísticas. Para el procesamiento de los datos utilizamos el software SPSS y para la elaboración del informe utilizamos el programa Microsoft Office.

\section{FORMULACIÓN Y SISTEMATIZACIÓN DEL PROBLEMA}

La situación antes descrita permite plantear y precisar respondiendo a la siguiente pregunta general:

¿Cuán determinante es el clima organizacional en la satisfacción laboral de los colaboradores del Instituto Nacional Materno Perinatal?

La respuesta a esta pregunta se condiciona a la forma como se respondan a las siguientes preguntas específicas:

- P.E1. ¿Qué tanto influye el liderazgo y el conocimiento de los jefes en la creación de un ambiente laboral agradable que genere un mayor nivel de satisfacción en los colaboradores del Instituto Nacional Materno Perinatal?

- P.E2. ¿Es importante una adecuada comunicación entre los colaboradores con sus respectivos jefes superiores inmediatos en el
Instituto Nacional Materno Perinatal para que estén comprometidos con el desarrollo de la institución?

- P.E3. ¿El Instituto Nacional Materno Perinatal se preocupa por cubrir las necesidades de su personal al establecer incentivos laborales que aumenten la productividad, en un clima laboral adecuado?

- P.E4. ¿̇nfluye la reciprocidad entre los trabajadores y el Instituto Nacional Materno Perinatal en su satisfacción laboral?

\section{MARCO TEÓRICO}

\section{Clima organizacional}

\section{Definición del clima organizacional}

El clima organizacional hace referencia al ambiente psicosocial en el que se desenvuelven los miembros de una organización, dice relación con el trabajo "cotidiano y las metas estratégicas, aprovechando la oportunidad de utilizar una variable no económica para impactar sobre los resultados de la empresa o institución" (Marchant, 2003).

La teoría acerca del clima organizacional se remonta a las ideas de Tolman de los mapas cognitivos definidos como "el esquema individual que construyen las personas, para darle sentido a su ambiente" (Silva, 1992). Enfocando aspectos organizacionales, Lewin (1939) relaciona comportamiento humano y ambiente a través del concepto de "atmósfera psicológica" en referencia a una realidad empírica susceptible de ser demostrada, como un "patrón relativamente duradero y estable de acciones e interacciones de la gente en la organización y que constituye un conjunto de fuerzas sociales sobre el individuo en ese ambiente".

A mediados de 1960, la investigación sobre clima laboral se centró en las cualidades subjetivas (Likert, 1961) señalando cómo una atmósfera de trabajo, que mantiene un clima de apoyo, genera un mejor nivel en el rendimiento de los sujetos. Así mismo, Litwin y Stringer (1968) realizaron un experimento similar al de Lewin (1939), concluyendo que la posibilidad de crear diferentes climas en las organizaciones depende de los estilos de liderazgo así como de la activación de componentes de la motivación, el desempeño y la satisfacción, provocando cambios aparentemente estables en los rasgos de personalidad (Astudillo, 1985). 
El concepto de clima (Rodríguez, 1992), apunta a "[...] las percepciones compartidas por los miembros de una organización respecto al trabajo, el ambiente físico en que éste se da, las relaciones interpersonales que tienen lugar en él y las diversas regulaciones formales que afectan dicho trabajo". Complementariamente, Litwin y Stringer (1968) entendieron clima como "[...] un conjunto de propiedades medibles del medio ambiente de trabajo, percibidas directa o indirectamente por las personas que trabajan en la organización y que influencian su motivación y comportamiento".

El clima organizacional es una característica de las organizaciones (Schneider y Snyder, 1975), que se desprende de las descripciones que los sujetos realizan acerca de las políticas, prácticas y condiciones que existen en el ambiente de trabajo (Lotito, 1992). En consecuencia, el clima se refiere a "[...] la percepción que los miembros de una organización tienen de las características que la describen y la diferencian de otras organizaciones, influyendo estas percepciones en el comportamiento organizacional de los miembros" (Justiniano, 1984).

También se lo ha definido como "[...] el sistema predominante de valores de una organización [...] combinando las diferentes características personales de los individuos, para hacer que una organización sea más efectiva" (Katz y Kahn, 1966). En tanto que Martínez (2001) señaló el clima organizacional "[...] es un fenómeno interviniente que media entre los factores del sistema organizacional y las tendencias motivacionales que se traducen en un comportamiento que tiene consecuencias para la organización (productividad, satisfacción, rotación, entre otros)". A su vez, Campbell et al. (1970) definen clima como un "[...] conjunto de atributos específicos de una organización particular dentro de la organización que pueden ser inducidos por el modo como la organización se enfrenta con sus miembros y su entorno".

Por su parte, Schneider y Snyder (1975) manifestaron que el clima es un atributo del individuo y por lo tanto, es una percepción que se realiza del ambiente. Desde su visión, "[...] las percepciones del clima son descripciones para caracterizar las prácticas y procedimientos de un sistema" (Justiniano, 1984). Por otro lado, James y Sells (1981), en
Silva, (1992), indicaron que "[...] el clima son representaciones cognitivas del individuo de eventos situacionales relativamente cercanos, expresado en términos que reflejan el significado psicológico y el significado de la situación para el individuo".

Como corolario, el clima organizacional es el conjunto de apreciaciones que los miembros de una organización tienen de su experiencia en el sistema organizacional y que se sintetiza en cuatro ideas fundamentales (Justiniano, 1984): el clima se refiere a la percepción de los miembros de la organización; que no necesariamente refleja la realidad tal cual es; que es fundamental conocer las percepciones que tienen las personas de la organización; y que la existencia de un clima que caracteriza a cada organización, diferencia una de otra.

\section{Características del clima institucional}

Existen una serie de características del clima laboral que son importantes de conocer (Chiavenato, 2000, p. 119). El clima laboral hace referencia a la situación en que tiene lugar el trabajo de la organización. Las variables que definen el clima laboral, son aspectos que guardan relación con el ambiente laboral. El clima se refiere a las características del medio ambiente de trabajo.

El clima de una organización tiene una cierta permanencia a pesar de experimentar cambios por situaciones coyunturales. Toda organización puede contar con cierta estabilidad de clima, con cambios que pueden ser regulables pero, de la misma manera, la estabilidad puede sufrir perturbaciones de importancia, resultados de decisiones que, en consecuencia, afectan el bienestar de la organización. Un mal entendido que no haya sido resuelto en su momento puede traer como consecuencia un deterioro de clima laboral, ya que puede pasar un buen tiempo para que se esclarezca el problema. El clima laboral tiene un fuerte impacto sobre los comportamientos de los miembros de la Institución.

El ambiente de trabajo influye de manera positiva o negativa en el comportamiento de los miembros de una organización. Si se mantiene un clima favorable, los trabajadores 
se desenvolverán con mayor eficiencia y con ánimos de desempeñarse mejor, entregando lo mejor de sí en la organización, y si existe un clima malo será todo lo contrario a lo que se dijo anteriormente. El clima laboral afecta el grado de compromiso e identificación de los miembros de la organización con ésta.

Las organizaciones que mantengan un buen clima laboral tendrán como resultados colaboradores contentos, satisfechos y por consiguiente, se identificarán y sentirán comprometidos con la organización para retribuir mejor con los objetivos de la misma. Por otro lado, si se mantiene un clima desfavorable, una de las consecuencias será que la organización no tendrá colaboradores comprometidos ni mucho menos identificados.

Por otro lado, el clima laboral es afectado por los comportamientos y actitudes de los miembros de la organización. Un miembro de la organización puede darse cuenta que el clima laboral es agradable e inconscientemente, con su buen comportamiento, está aportando a la entidad a mantener un eficiente clima laboral; de la misma forma, en caso contrario, en la institución en estudio se observó que existen miembros de la organización que con su comportamiento negativo contribuyen a que el clima de trabajo sea negativo, trayendo como consecuencia insatisfacción en los demás colaboradores.

El clima laboral de una organización es afectado por diferentes variables estructurales, tales como estilo de dirección, políticas y planes de gestión, sistemas de contratación y despidos, etc. Tales variables, a su vez, afectan al clima organizacional. En organizaciones con gestión autoritaria los colaboradores se desempeñarán con miedo, temor, y si no existe confianza hacia los trabajadores, se generará un clima tenso. Dicho clima llevará a actuar a los empleados con irresponsabilidad; para obtener resultados su jefe controlará más sus actividades y ello conllevará a un ambiente de descontento tanto para los trabajadores como para los empleadores.

El ausentismo y la rotación excesiva pueden ser indicadores de un clima laboral anómalo. Toda organización presenta ausentismo de su personal, algunas pueden ser de manera involuntaria como también voluntaria. Por lo general, cuando suelen ser voluntarias, son síntomas que la persona no se sienten bien en el lugar donde labora y si este malestar continúa optan por renunciar al trabajo, generando así una alta rotación del personal, ya que se vive un pésimo clima laboral.

\section{Dimensiones del clima institucional}

El comportamiento de un trabajador es resultante de los factores organizacionales existentes, y esto depende de las percepciones que tenga sobre estos factores. Estas dimensiones miden la percepción del clima, se traducen en un cuestionario que es el instrumento frecuentemente utilizado para medir el clima organizacional en una Institución

El cuestionario desarrollado por Litwin y Stringer (1968) mide la percepción de los empleados en función de nueve dimensiones.

- Estructura. Son las opiniones de los trabajadores acerca de las limitaciones que hay en el grupo, se refiere a cuantas reglas, reglamentos y procedimientos se dan en la organización. Representa la percepción que tiene los miembros de la organización, limitaciones a que se ven enfrentados en el desarrollo de su trabajo acerca de la cantidad de reglas, procedimientos, trámites y otras.

- Responsabilidad (empowerment). Es la virtud que tiene cada miembro de la organización para asumir las consecuencias que generen sus propias decisiones que tomen en la organización. Es el sentimiento de los miembros de la organización acerca de su autonomía en la toma de decisiones relacionadas a su trabajo.

- Recompensa. Es una forma de motivar al empleado cuando realiza un buen trabajo. Se sabe que los factores de motivación intrínseca son importantes para el individuo. Los trabajadores tienen una percepción de equidad cuando su trabajo realizado está bien hecho. Corresponde a la percepción de los miembros la adecuación de la recompensa recibida por el trabajo bien hecho. Es la medida en que la organización utiliza más el premio que el castigo.

- Desafío. Toda organización establece desafíos entre los miembros de trabajo y, de 
esa forma, generan competencia, logrando así objetivos personales y laborales. Corresponde al sentimiento que tienen los miembros de la organización acerca de los desafíos que impone el trabajo. Es la medida en que la organización promueve la aceptación de riesgos calculados a fin de lograr los objetivos propuestos.

- Relaciones. Es la percepción que tiene los trabajadores acerca de las relaciones sociales que los une en el ambiente de trabajo a los empleadores y empleados. Es la percepción por parte de los miembros de la institución acerca de la existencia de un ambiente de trabajo grato y de buenas relaciones sociales tanto entre pares como entre jefes y subordinados.

- Cooperación. Los miembros perciben que hay apoyo mutuo entre todos los que pertenecen a la organización. Es el sentimiento de los miembros de la Institución sobre la existencia de un espíritu de ayuda de parte de los directivos y de otros empleados del grupo. El énfasis está puesto en el apoyo mutuo, tanto de niveles superiores como inferiores.

- Estándares. Como se sabe, en toda organización existen lineamientos que se deben seguir para cumplir con lo que se delega. Es la percepción de los miembros acerca del énfasis que ponen las organizaciones sobre las normas de rendimiento.

- Conflictos. Se da cuando entre los miembros de la organización existen diferencias u oposiciones con respecto algún tema Es el sentimiento del grado en que los miembros de la organización, tanto pares como superiores, aceptan las opiniones discrepantes y no temen enfrentar y solucionar los problemas tan pronto surjan.

- Identidad. Es lo que genera todo trabajador satisfecho al identificarse y comprometerse con la organización, logrando los objetivos de la institución como también los personales. Es el sentimiento de pertenencia a la organización y es un elemento importante y valioso dentro del grupo de trabajo. En general, es la sensación de compartir los objetivos personales con los de la organización.

\section{Factores que condicionan el clima institucional}

- Motivación. La motivación es una actitud necesaria para que la persona se sienta cómoda en su trabajo, se desempeñe en el con ánimo e incluso logre su realización personal. Siempre nos vemos motivados por algo para realizar una determinada actividad, y nos movemos con mayor agilidad mientras más motivación exista. Nos atrevemos a decir que así funcionamos los seres humanos y que hoy en día el medio nos obliga a avanzar para, de esta manera, cumplir nuestros objetivos. La motivación es la "[...] influencia sobre los trabajadores para crear en ellos el deseo de alcanzar un determinado objetivo" (Pérez y Villalba, 2002: 332). Así mismo, Robbins y Coulter dicen que la motivación "[...] Es la voluntad de desarrollar altos niveles de esfuerzo para alcanzar las metas organizacionales, bajo la condición de que dicho esfuerzo ofrezca la posibilidad de satisfacer alguna necesidad individual" (Robbins y Coulter, 2000: 484).

- Comunicación. La comunicación es un elemento importante para poder conectar al individuo, el grupo y la organización, ya que nadie puede tomar decisiones sin tener información respecto a lo que fuera, por eso esta información debe ser comunicada a todos los que pertenezcan a la organización. Por ello la dirección o cualquier miembro de la institución, cuando toman decisiones, deben utilizar cualquier medio de comunicación para darla a conocer. Es cierto que cualquier Institución que maneja una deficiente comunicación, por lo general, no logra sus objetivos. Hodgetts y Altman definen a la comunicación como "[...] el proceso de transmitir significados que van del emisor al receptor" (1985: 324). Así mismo Robbins y De Cenzo definen la comunicación como "transferir y comprender el significado". (2000, p. 341). Estas definiciones de ambos autores nos permiten entender que la comunicación no solo es expresar ideas o información sino también que éstas se deben comprender.

\section{Factores que afectan el clima institucional}

Para que un administrador logre que su grupo trabaje con entusiasmo es necesario que lo mantenga altamente motivado. Algunas veces 
esto no es fácil, debido a que existen grupos heterogéneos con necesidades diferentes y muchas veces desconocidas.

Según Werther y Davis (1995: 115) hay variables que afectan la motivación dentro de las organizaciones:

- Las características individuales son las que posee cada trabajador respecto a intereses, percepciones y personalidad, que son disimiles de otros. Es por ello que cada uno tiene diferentes necesidades y, por ende, motivaciones distintas.

- Los intereses, actitudes y necesidades que una persona trae a una organización difieren de las de otras personas, por tanto sus motivaciones serán distintas.

- Las características del trabajo son todas las actividades que realizan los trabajadores en su centro de labor y, como consecuencia de ello, podrán cubrir sus expectativas. "Son aquellas inherentes a las actividades que va a desempeñar el empleado y que pueden o no satisfacer sus expectativas personales" (Werther y Davis, 1995).

- Las características de la situación de trabajo son el conjunto de factores que intervienen en el ambiente de trabajo que, a su vez, influye de manera positiva en los miembros de la organización. "Son los factores del ambiente laboral del individuo, factores éstos que se traducen en acciones organizacionales que influyen y motivan a los empleados" (Werther y Davis, 1995).

\section{Satisfacción laboral}

\section{Concepto de la satisfacción}

La satisfacción laboral es entendida como un factor que determina el grado de bienestar que una persona experimenta en su lugar de trabajo y está relacionado con el estado de ánimo y bienestar personal. Todas las personas tiene aspiraciones que no pueden ser ignoradas y si los directivos reconocen que el trabajo realizado por los miembros de la institución es bueno, generarán en ellos una plena satisfacción y, por consiguiente, mejorarán su desempeño.

"La satisfacción laboral es la sensación de bienestar que poseen los colaboradores en su centro de labor" (Gibson et al., 1996: 48). La satisfacción en el trabajo es importante en cualquier tipo de profesión, no solo en términos de bienestar de las personas, sino también en términos de calidad y productividad.

\section{Modelos de satisfacción del trabajo}

El concepto "estar satisfecho en el trabajo" lo entendemos según la definición de Herzberg et al. (1959), como aquellas sensaciones que tenemos hacia el trabajo y con el trabajo (agrado o desagrado, buenas o malas relaciones humanas, aceptación o no de situaciones laborales, posibilidad de crecimiento profesional, condiciones del medio laboral, etc.).

La teoría de los dos factores en el modelo de satisfacción de Herzberg et al. (1959), con relación a la satisfacción e insatisfacción producida en el ambiente laboral, presenta como elementos no necesariamente relacionados los denominados factores intrínsecos o motivacionales y los factores higiénicos extrínsecos. Los factores intrínsecos son aquellos que aluden a la propia situación interna de la organización produciendo satisfacción cuando estén presentes en las condiciones idóneas, mientras que los factores extrínsecos e higiénicos generan insatisfacción cuando no se encuentren presentes, pero no satisfacción cuando sí los tenemos.

Es una evidencia de la percepción que tiene el trabajador sobre su trabajo y la respuesta que da a determinadas situaciones que se provocan en su desempeño laboral. El modelo de satisfacción anticipada (modelo de la valencia), nos presenta una satisfacción que se condiciona a lo que se espera conseguir en el futuro. Vroom (1964), como máximo exponente de este modelo de "satisfacción anticipada", expone que el sujeto llega a generar expectativas sobre algo que desea como consecuencia de unas experiencias o vivencias pasadas.

La teoría de ajuste en el trabajo (Davis y Newstrom, 1963) presenta un modelo teórico en donde el equilibrio entre el sujeto, su medio en el que se han cubierto sus necesidades y el reconocimiento que sienten los demás al valorar su actuación, constituye la satisfacción del trabajador en su contexto laboral. La satisfacción por el trabajo realizado es una causa potencial de más rendimiento o, por el contrario, causa de ausentismo laboral (Hackett, 1989).

Una perspectiva centrada en el análisis entre satisfacción y rendimiento se presenta en 
el modelo de satisfacción de facetas (Lawer, 1973), en donde se relaciona la satisfacción y el nivel de rendimiento en función de la gratificación que obtiene el sujeto por su trabajo (económica, reconocimiento personal), y la percepción que este sujeto tiene de justicia y equidad respecto a esa gratificación o reconocimiento recibido.

Otro factor que debemos considerar ante la satisfacción laboral es el relacionado con el equilibrio entre la selección y distribución de personal en los puestos de trabajo y las expectativas del trabajador para ser seleccionado y distribuido (Davis y Newstrom, 1963). Debe haber satisfacción del sujeto y de la empresa con su trabajo para alcanzar el rendimiento previsto.

La teoría de la discrepancia de Locke (1984) explicita que la satisfacción laboral ira en función de lo que recibe la persona, en relación a lo que espera, y en las consecuencias que le reportara el hacer su trabajo (lo que hace en relación con lo que recibe). En este modelo aparecen dos facetas. Una en la que se plantea lo que el individuo ha dado en el trabajo, y otra en la que se valora lo que podría haber dado. Si ambas no están equilibradas, se produce una insatisfacción laboral al no estar el trabajador satisfecho con el trabajo realizado.

Entre los enfoques teóricos sobre la satisfacción laboral sobresale el modelo de Hulin et al. (1985) que resume los elementos de otros modelos, relacionando algunos procesos con el rol que desempeña el sujeto y sus consecuencias positivas, llegando a la conclusión que los factores que inciden e influyen en la satisfacción laboral son aquellos que benefician nuestro trabajo (tiempo necesario, poseer el esfuerzo que se requiere, así como la habilidad, técnica, destreza y formación que se solicita) y dan buenos resultados que se premian o gratifican (incentivos, reconocimiento profesional, mejora de condiciones laborales). Este modelo, denominado "modelo de afecto al rol" expone las variaciones de niveles de satisfacción que pueden producirse en función de hechos pasados y presentes. Posteriormente Hulin (1991) efectuó una revisión de los modelos de actitud hacia el trabajo, establecidos con anterioridad por March y Simon (1958), y Herzberg et al. (1959).
Para Hulin (1991), tal y como expone Sáez (1997), no son excluyentes los modelos de "satisfacción anticipada" y de "afecto al rol" al entender que cuando hemos tenido satisfacción en experiencias pasadas, podemos intuir la satisfacción que nos proporcionarán en el futuro, y esa experiencias pasadas determinarán nuestro presente en lo referido a la satisfacción.

Otras teorías sobres condicionantes o factores influyentes en la satisfacción laboral nos aportan una visión diferente a las anteriormente citadas. De este modo encontramos que según Quarstein (1992), existen factores presentes en el ámbito laboral que se valoran antes de ocupar el puesto, puede ser el tipo y estilo de dirección, la remuneración económica que se nos ofrece o las posibilidades de formación continuada y crecimiento profesional, etcétera, y otros factores que valora el sujeto después de iniciar su trabajo en el puesto correspondiente.

Ante estos dos tipos de factores, se producen respuestas en lo referido al sentimiento y emociones que generarán más o menos satisfacción laboral dependiendo de las características del trabajador y sus reacciones ante estos factores. Quarstein (1992) define este modelo como "Modelo de eventos situacionales" ya que las situaciones que se van produciendo marcarán esas respuestas del sujeto y habrá más o menos satisfacción dependiendo del control que se tenga sobre esas situaciones.

Büssing (1992), en su modelo sobre satisfacción laboral, relacionando con las teorías de Quarstein (1992), expone la importancia que tiene el control de las situaciones, al entender que la satisfacción está permanentemente asociada a las situaciones y características del trabajo. Afirma que no solo se trata de estar satisfecho sino también de analizar cómo es esa satisfacción, ya que se puede estar satisfecho por situaciones que se tienen y se deseaban, o no tener esa satisfacción por situaciones que se tienen existentes, con las que nos conformamos por no tener otra alternativa.

El enfoque dado nos muestra que, dependiendo de la discrepancia o afinidad entre lo que se espera de las características y situaciones del trabajo y de lo que realmente ocurre, tendremos más o menos satisfacción laboral. Rompe pues con otras teorías donde más importante es la cantidad de satisfacción a diferencia de 
ésta, donde se valora la cantidad y calidad de esa satisfacción.

Büssing (1992) expone en su modelo hasta seis formas de satisfacción laboral (satisfacción progresiva, satisfacción estabilizada, satisfacción resignada, insatisfacción constructiva, insatisfacción fija y pseudo-satisfaccion laboral) que, tal y como afirma Sáez (1997), pasan por tres secuencias para lograr estos tipos de satisfacción:

- Equilibrio entre expectativas, necesidades y motivos con la situación del trabajo.

- Llegar al cambio en el nivel de aspiraciones.

- Conducta para la resolución de problemas y su afrontamiento.

Respecto a las diferentes opiniones sobre qué es lo que produce la satisfacción en el trabajo, autores como Price (1981) sostienen que la satisfacción llega por una orientación afectiva que el profesional tiene hacia su trabajo por las condiciones en que se desarrolla. Por el contrario, Lu (2007) afirma que la satisfacción e insatisfacción no dependerá de la naturaleza del trabajo o sus condiciones laborales, sino de las perspectivas del futuro que en él se ve el trabajador, teoría más cercana a la de Conrad (1985) que fundamentada en la teoría tradicional de Maslow, expone que la satisfacción aparece en función de las posibilidades de realización del trabajador al alcanzar así el vértice de la pirámide al cubrir sus necesidades de autorrealización personal.

\section{Predictores de alteraciones de la satisfacción laboral}

Si nos centramos en la satisfacción laboral en el sector salud no podemos obviar la situación que los profesionales de la salud viven respecto a su cercanía con los procesos de dolor y muerte. Es en este ámbito de trabajo donde profesionales como las enfermeras desarrollan su actividad profesional y encuentran elementos de riesgo psicosocial que inciden en sus niveles de satisfacción laboral.

Entre esos elementos está la multiculturalidad con su diversidad de costumbres, lenguas, creencias, ideologías y formas de afrontamiento ante los procesos de enfermedad y muerte por parte del cliente-paciente, lo que demanda una especial preparación del personal sanitario y requiere de estrategias concretas para dominar esas barreras y obstáculos que se presentan cuando las personas no tienen la misma forma de entender y asumir la enfermedad, el dolor y la propia muerte (García y Cruz, 2008).

Esto constituye un obstáculo para una adecuada prestación de la asistencia sanitaria (Bischoff, 1999) y requiere de una comunicación entre enfermera y paciente para dar respuestas a sus necesidades en materia de salud (Leno, 2006; Zimmermann, 2000), y atender y valorar esa ansiedad y miedo que domina al individuo ante el dolor y la muerte (Marshall, 1981), respetando siempre su culturalidad.

La satisfacción laboral también tiene una estrecha relación con el puesto de trabajo y sus características, lo que da respuestas específicas a actividades y tareas (Cruz, 2006). Elementos como los tipos de actividades que encierran las funciones del puesto, la carga de trabajo existente con relación a los recursos disponibles o el reconocimiento profesional a su labor cotidiana por sus compañeros y superiores, condicionan la satisfacción del sujeto (Muchinsky, 2002).

Es una evidencia documentada que los bajos niveles de satisfacción laboral se traducen en bajos rendimientos cuando la demanda de trabajo opera a los recursos existentes. De igual modo el nivel de responsabilidad y dificultad en el desempeño de funciones, la toma de decisiones que se asumen (Bravo et al., 1996), las horas de dedicación exigida y la retribución económica asignada a ese puesto (Robles-García, 2005), son también elementos importantes que condicionan el bienestar del trabajador.

Otro aspecto que constituye un importante factor a tener en cuenta a la hora de medir la satisfacción laboral es la relación entre el trabajador y las jerarquías superiores (Robles-García, 2005), así como el nivel de satisfacción que siente el sujeto al realizar su trabajo en función de lo agradable y rutinario que le parezca, y el equilibrio existente entre sus capacidades, habilidades y conocimientos para realizar la actividad y tarea exigida, y lo que pide de ese trabajo (Spector, 1992). Esta última teoría es vieja en el tiempo ya que desde finales del siglo XIX, con las teorías de Taylor, se propugnaba 
la necesidad de adaptar el trabajo al trabajador y el trabajador al trabajo, como hecho imprescindible para un buen desempeño de actividades laborales y alcance de objetivos, con el consecuente incremento de la satisfacción del trabajador.

\section{OBJETIVOS DE LA INVESTIGACIÓN}

Para la presente investigación se plantearon los siguientes objetivos de trabajo:

\section{Objetivo general}

Identificar y proponer estrategias que permitan mejorar la gestión del Instituto Nacional Materno Perinatal-Ministerio de Salud en la mejora de la satisfacción del personal.

\section{Objetivos específicos}

- Demostrar que el liderazgo tiene influencia en la satisfacción laboral.

- Determinar si la comunicación es factor influyente en la satisfacción laboral de los colaboradores de INMP.

- Explicar si la motivación es un aspecto fundamental en la satisfacción laboral de los trabajadores.

- Determinar si la reciprocidad influye en la satisfacción laboral en los trabajadores del INMP.

\section{HIPÓTESIS DEMOSTRADA}

De la misma forma se planteó la siguiente hipótesis general:

\section{Hipótesis general}

El clima organizacional en el Instituto Especializado Materno Perinatal influye en el nivel de satisfacción de sus colaboradores.

De acuerdo con las premisas establecidas por la academia, la mencionada hipótesis general se puede comprobar a través de las hipótesis secundarias o específicas, que para la presente investigación son los siguientes:

\section{Hipótesis específicas}

\section{Hipótesis a}

- H0: El liderazgo y conocimiento de los jefes no genera un mayor nivel de satisfacción en los colaboradores del Instituto Nacional Materno Perinatal.

- H1: El liderazgo y conocimiento de los jefes sí genera un mayor nivel de satisfacción en los colaboradores del Instituto Nacional Materno Perinatal.

\section{Hipótesis b}

- H0: No es importante una adecuada comunicación entre colaboradores y sus jefes para que estén comprometidos con el desarrollo del Instituto Nacional Materno Perinatal.

- H1: Sí es importante una adecuada comunicación entre colaboradores y sus jefes para que estén comprometidos con el desarrollo del Instituto Nacional Materno Perinatal.

\section{Hipótesis c}

- H0: Los incentivos que ofrece el Instituto Nacional Materno Perinatal no aumentan la productividad de los colaboradores ni generan un clima laboral adecuado.

- H1: Los incentivos que ofrece el Instituto Nacional Materno Perinatal sí aumentan la productividad de los colaboradores y generan un clima laboral adecuado.

\section{Hipótesis d}

- H0: La reciprocidad entre los trabajadores y el Instituto Nacional Materno Perinatal no influye en la satisfacción laboral.

- H1: La reciprocidad entre los trabajadores y el Instituto Nacional Materno Perinatal sí influye en la satisfacción laboral.

\section{METODOLOGÍA Y TÉCNICAS DE INVESTIGACIÓN UTILIZADAS}

La investigación se realizó utilizando el método científico, vale decir métodos y procedimientos de investigación que nos permiten solucionar problemas institucionales y establecer mecanismos que sean científicamente válidos para la solución de problemas similares en otras instituciones de salud. Como parte del trabajo de campo realizamos una recopilación de datos mediante encuestas al personal del Instituto Nacional Materno Perinatal. Se analizaron los resultados haciendo uso de procedimientos estadísticos y programas informáticos, complementados con la observación y la entrevista. 


\section{Población y muestra}

El universo de la población investigada involucró a todos los miembros del Instituto Nacional Materno Perinatal; teniendo como referencia los roles que cumplen actualmente ya sea por funciones asignadas o por el nivel de formación que tienen.

\section{Muestra}

La muestra se determinó teniendo en cuenta el universo de los miembros de la alta dirección, jefaturas intermedias y operativas, y los trabajadores, se obtuvo a través de una muestra aleatoria simple, obteniendo un resultado de 316 de un total de 1,780 trabajadores $(1,380$ nombrados, 400 contratados, entre ellos 150 administrativos y 1,400 asistentes) del Instituto Nacional Materno Perinatal.

\begin{tabular}{|l|}
\hline DATOS: \\
\hline Población $(\mathrm{N}): \mathrm{N}=1780$ \\
\hline $\mathrm{P}:$ Desconocido entonces, $\mathrm{P}=0.5$ y Q $=0.5$ \\
\hline E: Este valor depende del investigador (recomendable $=5 \%)$ \\
\hline : Desconocido entonces, $=5 \% ; 1$ - = 95\%; $/ 2=2.5 \%$ \\
\hline $\mathrm{Z} \%=1.96$ (Tabla de Distribución Normal) \\
\hline $\mathrm{n}=?$ \\
\hline
\end{tabular}

Entonces: $\quad \mathrm{n}_{0}=\left(\mathrm{Z}^{2 *} \mathrm{~S}^{2}\right) / \mathrm{d}^{2}$

Dónde:

S2: Varianza

d2: Error de precisión

Reemplazando valores en la formula se tiene: $\mathrm{n} 0=\left[(1.96)^{2}(0.5) 2\right] /[(0.05) 2]=384.16$

Como nuestra unidad muestral (sujeto, elemento) está conformada por el total de trabajadores del Instituto Nacional Materno Perinatal se tomarán 384 para realizar el estudio. Por tanto tenemos:

$$
\begin{aligned}
& \mathrm{n}=\mathrm{n} 0 /(1+\mathrm{n} 0 / \mathrm{N}) \\
& \mathrm{n}=384.16 /(1+384.16 / 1780)=115.97 \approx 115
\end{aligned}
$$

Entonces, se concluye encuestar del total de trabajadores a 316 colaboradores. El trabajo de campo se realizó utilizando el método de muestreo aleatorio simple, esto es todos los elementos de la población tienen las mismas posibilidades de ser elegidos.

\section{RECOLECCIÓN E INTERPRETACIÓN DE DATOS}

En esta parte vamos a analizar e interpretar los datos trabajados a través de los estadígrafos.

\section{Pregunta 1}

Los directivos y/o jefes solucionan problemas de manera creativa y buscan constantemente la innovación y las mejoras.

\section{Cuadro 1}

\begin{tabular}{|l|l|c|c|c|c|}
\hline & & Frecuencia & Porcentaje & $\begin{array}{c}\text { Porcentaje } \\
\text { válido }\end{array}$ & $\begin{array}{c}\text { Porcentaje } \\
\text { acumulado }\end{array}$ \\
\hline Válidos & NO BUSCAN & 34 & 29.6 & 29.6 & 29.6 \\
\cline { 2 - 6 } & PROMEDIO & 51 & 44.3 & 44.3 & 73.9 \\
\hline & PERMANENTE & 30 & 26.1 & 26.1 & 100.0 \\
\hline
\end{tabular}

\section{Análisis interpretativo}

Los resultados obtenidos de la pregunta si los directivos y/o jefes solucionan problemas de manera creativa y buscan constantemente la innovación y las mejoras, para los trabajadores del INMP, el $30 \%$ menciona que no buscan, que sus jefes solucionan problemas de manera creativa, el $44.3 \%$ dice que el comportamiento de los directivos es promedio, y el $26.1 \%$ opinan que buscan soluciones de modo permanente. Como se puede verificar hay una posición relativa en cuanto a este punto pues la mayoría piensa en promedio que sus jefes solucionan problemas creativamente.

\section{Pregunta 2}

Los directivos y jefes demuestran un dominio técnico y conocimiento de sus funciones.

Cuadro 2

\begin{tabular}{|l|l|c|c|c|c|}
\hline & & Frecuencia & Porcentaje & $\begin{array}{c}\text { Porcentaje } \\
\text { válido }\end{array}$ & $\begin{array}{c}\text { Porcentaje } \\
\text { acumulado }\end{array}$ \\
\hline Válidos & NO PROPORCIONAN & 32 & 27.8 & 27.8 & 27.8 \\
\hline & INDISTINTO & 57 & 49.6 & 49.6 & 77.4 \\
\hline & PROPORCIONAN & 26 & 22.6 & 22.6 & 100.0 \\
\hline & Total & 115 & 100.0 & 100.0 & \\
\hline
\end{tabular}

\section{Análisis interpretativo}

En relación a que los directivos y jefes demuestran un dominio técnico y conocimiento de sus funciones, un $27 \%$ dicen demostrar tales conocimientos, mientras un $54.8 \%$ son indiferentes. De la misma forma el $18.3 \%$ de los encuestados dicen que los directivos y/o jefes no demuestran un dominio técnico, tampoco conocimiento de sus funciones. 


\section{Pregunta 3}

El INMP me proporciona información oportuna y adecuada de mi desempeño y resultados alcanzados.

\section{Cuadro 3}

\begin{tabular}{|l|l|c|c|c|c|}
\hline & & Frecuencia & Porcentaje & $\begin{array}{c}\text { Porcentaje } \\
\text { válido }\end{array}$ & $\begin{array}{c}\text { Porcentaje } \\
\text { acumulado }\end{array}$ \\
\hline Válidos & D. INDIVIDUALES & 27 & 23.5 & 23.5 & 23.5 \\
\hline & INDIFERENTE & 63 & 54.8 & 54.8 & 78.3 \\
\hline & D. PARTICIPATIVAS & 25 & 21.7 & 21.7 & 100.0 \\
\hline & Total & 115 & 100.0 & 100.0 & \\
\hline
\end{tabular}

\section{Análisis interpretativo}

El siguiente cuadro representa el nivel de información oportuna y adecuada que proporciona el INMP a sus trabajadores. Así, el 27.8\% piensa que no proporcionan, mientras que el $49.6 \%$ sostiene que es indistinto y el $22.6 \%$ manifiesta que no proporcionan. Así se puede ver que la mayoría de ellos siguen pensando que para ellos es indistinto que proporcionen o no información oportuna y adecuada de su desempeño laboral, así como de los resultados alcanzados.

\section{Pregunta 4}

Los directivos y jefes toman decisiones con la participación de los trabajadores del establecimiento.

\section{Cuadro 4}

\begin{tabular}{|l|l|c|c|c|c|}
\hline & & Frecuencia & Porcentaje & $\begin{array}{c}\text { Porcentaje } \\
\text { válido }\end{array}$ & $\begin{array}{c}\text { Porcentaje } \\
\text { acumulado }\end{array}$ \\
\hline Válidos & D. INDIVIDUALES & 27 & 23.5 & 23.5 & 23.5 \\
\hline & INDIFERENTE & 63 & 54.8 & 54.8 & 78.3 \\
\hline & D. PARTICIPATIVAS & 25 & 21.7 & 21.7 & 100.0 \\
\hline & Total & 115 & 100.0 & 100.0 & \\
\hline
\end{tabular}

\section{Análisis interpretativo}

Los resultados obtenidos de que si los directivos y jefes toman decisiones con la participación de los trabajadores del establecimiento, son los siguientes: el $23.5 \%$ sostienen que los directivos toman decisiones individuales, vale decir, sin tomar en cuenta las opiniones de los trabajadores; en tanto el $21.7 \%$ sostiene que sí toman decisiones con participación de los trabajadores. De la misma forma, el 54.8\% manifiesta que los directivos $\mathrm{y}$ jefes toman decisiones indistintamente, vale decir, con o sin tomar en cuenta las opiniones de los trabajadores.

\section{Pregunta 5}

Los directivos del centro laboral hacen los esfuerzos necesarios para mantener informados oportunamente a los trabajadores sobre los asuntos que nos afectan e interesan, así como del rumbo de la institución.

Cuadro 5

\begin{tabular}{|c|c|c|c|c|c|}
\hline & & Frecuencia & Porcentaje & $\begin{array}{c}\text { Porcentaje } \\
\text { válido }\end{array}$ & $\begin{array}{c}\text { Porcentaje } \\
\text { acumulado }\end{array}$ \\
\hline Válidos & NO INFORMAN & 32 & 27.8 & 27.8 & 27.8 \\
\hline & INDIFERENTE & 61 & 53.0 & 53.0 & 80.9 \\
\hline & INFORMADOS & 22 & 19.1 & 19.1 & 100.0 \\
\hline & Total & 115 & 100.0 & 100.0 & \\
\hline
\end{tabular}

\section{Análisis interpretativo}

Los resultados son claramente aleccionadores al respecto: solo el $19.1 \%$ manifiesta que los directivos mantienen informados sobre asuntos de interés a los trabajadores, mientras que el 27.8\% dice que no informan. En este como en las anteriores, el 53\% de los encuestados sostienen que el comportamiento de los directivos es indistinto, vale decir que algunas veces informan y en otros no, evidenciándose una posición media pues concluyen que los directivos del centro laboral tienen un comportamiento indistinto para mantener informados oportunamente a los trabajadores sobre los asuntos que nos afectan e interesan, así como del rumbo de la institución donde trabajan.

\section{Pregunta 6}

Estoy satisfecho con los procedimientos establecidos por la institución para resolver los reclamos de los trabajadores.

Cuadro 6

\begin{tabular}{|c|c|c|c|c|c|}
\hline & & Frecuencia & Porcentaje & $\begin{array}{c}\text { Porcentaje } \\
\text { válido }\end{array}$ & $\begin{array}{c}\text { Porcentaje } \\
\text { acumulado }\end{array}$ \\
\hline Válidos & NO SATISFECHO & 26 & 22,6 & 22,6 & 22,6 \\
\hline & INDIFERENTE & 73 & 63,5 & 63,5 & 86,1 \\
\hline & SATISFECHO & 16 & 13,9 & 13,9 & 100,0 \\
\hline & Total & 115 & 100,0 & 100,0 & \\
\hline
\end{tabular}

\section{Análisis interpretativo}

Los resultados obtenidos de que sí están satisfechos con los procedimientos disponibles para resolver los reclamos de los trabajadores son los siguientes: el $22.6 \%$ manifiesta no estar satisfecho; $63.5 \%$, es indiferente y el $13.9 \%$, satisfechos. Con tales resultados se puede colegir que la mayoría de ellos (63.5\%) dice que le es indiferente que la institución instituya procedimientos para canalizar los reclamos de sus trabajadores. 


\section{Pregunta 7}

El ambiente de la institución permite expresar opiniones con franqueza, a todo nivel sin temor a represalias.

Cuadro 7

\begin{tabular}{|l|l|c|c|c|c|}
\hline & & Frecuencia & Porcentaje & $\begin{array}{c}\text { Porcentaje } \\
\text { válido }\end{array}$ & $\begin{array}{c}\text { Porcentaje } \\
\text { acumulado }\end{array}$ \\
\hline Válidos & NO PERMITE & 38 & 33.0 & 33.0 & 33.0 \\
\hline & INDISTINTO & 48 & 41.7 & 41.7 & 74.8 \\
\hline & PERMITE & 29 & 25.2 & 25.2 & 100.0 \\
\hline & Total & 115 & 100.0 & 100.0 & \\
\hline
\end{tabular}

\section{Análisis interpretativo}

Los resultados obtenidos de si el ambiente de la institución permite expresar opiniones con franqueza, a todo nivel sin temor a represalias son los siguientes: el 33\% manifiesta que no permite, mientras que el $41.7 \%$ dice que es indistinto, en tanto que el $25.2 \%$ dice que sí permiten. Tales resultados reflejan una tendencia que para la mayoría de los encuestados (41.7\%) es indistinto que el INMP instituya una política para expresar libremente sus puntos de vista, seguido de aquellos que manifiestan que no permiten.

\section{Pregunta 8}

El INMP se preocupa por las necesidades primordiales del personal.

\section{Cuadro 8}

\begin{tabular}{|l|c|c|c|c|c|}
\hline & & Frecuencia & Porcentaje & $\begin{array}{c}\text { Porcentaje } \\
\text { válido }\end{array}$ & $\begin{array}{c}\text { Porcentaje } \\
\text { acumulado }\end{array}$ \\
\hline Válidos & NO SE PREOCUPA & 47 & 40.9 & 40.9 & 40.9 \\
\hline & INDISTINTO & 52 & 45.2 & 45.2 & 86.1 \\
\hline & SE PREOCUPA & 16 & 13.9 & 13.9 & 100.0 \\
\hline & Total & 115 & 100.0 & 100.0 & \\
\hline
\end{tabular}

\section{Análisis interpretativo}

Los resultados obtenidos de si la institución se preocupa por las necesidades primordiales del personal son los siguientes: el $40.9 \%$ dice que no se preocupa, en tanto que el $45.2 \%$ dice que es indistinto que se preocupe o no se preocupe, mientras que el $13.9 \%$ dice que sí se preocupan. Con tales resultados se evidencia que la mayoría de los encuestados son indiferentes de si la institución se preocupa o no por las necesidades primordiales de sus colaboradores.

\section{Pregunta 9}

Los directivos y/o jefes generalmente me reconocen por un trabajo bien hecho.
Cuadro 9

\begin{tabular}{|c|c|c|c|c|c|}
\hline & & Frecuencia & Porcentaje & $\begin{array}{c}\text { Porcentaje } \\
\text { válido }\end{array}$ & $\begin{array}{c}\text { Porcentaje } \\
\text { acumulado }\end{array}$ \\
\hline Válidos & NO RECONOCEN & 35 & 30.4 & 30.4 & 30.4 \\
\hline & INDIFERENTE & 56 & 48.7 & 48.7 & 79.1 \\
\hline & RECONOCEN & 24 & 20.9 & 20.9 & 100.0 \\
\hline & Total & 115 & 100.0 & 100.0 & \\
\hline
\end{tabular}

\section{Análisis interpretativo}

Los colaboradores del INMP al ser consultados sobre el reconocimiento que se da por parte de los directivos o jefes inmediato superior con respecto al correcto desempeño de sus labores en beneficio de la institución, tenemos que la gran mayoría de encuestados califican en este punto como indiferente con un $48.7 \%$ que, de acuerdo a la proporcionalidad sería un aproximado de 867 trabajadores. De la misma forma el 30.4\% manifiesta que los directivos y jefes no reconocen por las labores bien realizadas. Finalmente solo el 20.9\% dice que los directivos y jefes sí reconocen los esfuerzos realizados en pro de la institución con un trabajo bien realizado

\section{Pregunta 10}

Tengo un conocimiento claro y transparente de las políticas y normas del personal del INMP.

Cuadro 10

\begin{tabular}{|l|l|c|c|c|c|}
\hline & & Frecuencia & Porcentaje & $\begin{array}{c}\text { Porcentaje } \\
\text { válido }\end{array}$ & $\begin{array}{c}\text { Porcentaje } \\
\text { acumulado }\end{array}$ \\
\hline Válidos & CONOCIMIENTO BAJO & 28 & 24.3 & 24.3 & 24.3 \\
\hline & CONOCIMIENTO MEDIA & 56 & 48.7 & 48.7 & 73.0 \\
\hline & CONOCIMIENTO ALTO & 31 & 27.0 & 27.0 & 100.0 \\
\hline & Total & 115 & 100.0 & 100.0 & \\
\hline
\end{tabular}

\section{Análisis interpretativo}

El cuadro muestra que el conocimiento de las políticas y normas de personal emprendidas en la institución no son satisfactorias ya que tan solo un $27 \%$ consideran que tienen un alto conocimiento y el resto que representa al 73\% (48.7\% conocimiento medio y $24.3 \%$ conocimiento bajo) manifiestan que no están enterados sobre estas normas llevadas por la institución. Esta situación puede ser ocasionada por la falta de estrategias comunicacionales de parte de los directivos acerca de las políticas y normas del personal por la institución. Ello significa que una gestión efectiva del personal debe tomar en cuenta tales percepciones. 


\section{Pregunta 11}

Los trabajadores son tratados bien, independientemente del cargo que ocupan.

Cuadro 11

\begin{tabular}{|c|c|c|c|c|c|}
\hline & & Frecuencia & Porcentaje & $\begin{array}{c}\text { Porcentaje } \\
\text { válido }\end{array}$ & $\begin{array}{c}\text { Porcentaje } \\
\text { acumulado }\end{array}$ \\
\hline Válidos & MAL TRATADOS & 36 & 31.3 & 31.3 & 31.3 \\
\hline & INDISTINTO & 57 & 49.6 & 49.6 & 80.9 \\
\hline & BIEN TRATADOS & 22 & 19.1 & 19.1 & 100.0 \\
\hline & Total & 115 & 100.0 & 100.0 & \\
\hline
\end{tabular}

\section{Análisis interpretativo}

A través de esta pregunta buscamos diagnosticar qué es lo que creen los trabajadores del INMP acerca del trato que reciben en su entorno laboral, independientemente del cargo o función que desempeñan, desde los altos directivos hasta los trabajadores. Al respecto se observa que el 31.3\% consideran que son mal tratados o mal considerados, siendo esta proporción muy importante para atender y tener en cuenta dado que representa casi a la tercera parte del total. Esto se puede mejorar con la organización de mayores eventos de integración entre trabajadores de las distintas áreas y responsabilidades dentro de la institución con la finalidad de eliminar esa brecha que aún persiste entre los trabajadores. Para el $49.6 \%$ es indistinto de la forma de como los directivos los tratan o consideran, en tanto que el $19.1 \%$ considera que se encuentran bien tratados, a pesar que el $68.7 \%$ opina lo contrario o próximo a ello.

\section{Pregunta 12}

En términos generales me siento satisfecho con mi centro laboral.

Cuadro 12

\begin{tabular}{|c|c|c|c|c|c|}
\hline & & Frecuencia & Porcentaje & $\begin{array}{c}\text { Porcentaje } \\
\text { válido }\end{array}$ & $\begin{array}{c}\text { Porcentaje } \\
\text { acumulado }\end{array}$ \\
\hline Válidos & INSATISFECHO & 21 & 18.3 & 18.3 & 18.3 \\
\hline & INDISTINTO & 61 & 53.0 & 53.0 & 71.3 \\
\hline & SATISFECHO & 33 & 28.7 & 28.7 & 100.0 \\
\hline & Total & 115 & 100.0 & 100.0 & \\
\hline
\end{tabular}

\section{Análisis interpretativo}

El presente cuadro muestra el nivel de satisfacción de los trabajadores del INMP que es parte fundamental en la reciprocidad (trabajador-institución e institución-trabajador) que es necesaria para el buen funcionamiento organizacional. Apreciamos que el $18.3 \%$ manifiesta su nivel de insatisfacción, el 53\% dice que es indistinto y el $28.7 \%$ sostiene que se encuentran satisfechos. Esta tendencia marca que para la gran mayoría (18.3\% y 53.0\%) se evidencia que la institución aún debe hacer algunos cambios o mejoras para aumentar la percepción positiva del centro laboral. Posiblemente este porcentaje sea la expresión de la reciente huelga médica que también afectó al INMP.

\section{Pregunta 13}

Considero que el trabajo que realiza mi jefe inmediato para manejar conflictos es bueno.

Cuadro 13

\begin{tabular}{|c|c|c|c|c|c|}
\hline & Frecuencia & Porcentaje & $\begin{array}{c}\text { Porcentaje } \\
\text { válido }\end{array}$ & $\begin{array}{c}\text { Porcentaje } \\
\text { acumulado }\end{array}$ \\
\hline Válidos & MALO & 36 & 31.3 & 31.3 & 31.3 \\
\hline & REGULAR & 49 & 42.6 & 42.6 & 73.9 \\
\hline & BUENO & 30 & 26.1 & 26.1 & 100.0 \\
\hline & Total & 115 & 100.0 & 100.0 & \\
\hline
\end{tabular}

\section{Análisis interpretativo}

Esta pregunta busca medir el grado de satisfacción/insatisfacción sobre la dimensión del liderazgo dentro de la institución. De esta manera los trabajadores consideran que el manejo de conflictos por parte de sus jefes es malo en un 31.3\%, regular $42.6 \%$ y bueno $26.1 \%$. Esto es preocupante porque el $73.9 \%$ (malo y regular) no está conforme con la labor de sus jefes en situaciones de conflicto, pudiendo ser un motivo de descontento en la relación laboral entre trabajadores y sus jefes.

\section{Pregunta 14}

Mi jefe inmediato se preocupa por crear un ambiente laboral agradable.

Cuadro 14

\begin{tabular}{|c|c|c|c|c|c|}
\hline & & Frecuencia & Porcentaje & $\begin{array}{c}\text { Porcentaje } \\
\text { válido }\end{array}$ & $\begin{array}{c}\text { Porcentaje } \\
\text { acumulado }\end{array}$ \\
\hline Válidos & NADA AGRADABLE & 27 & 23.5 & 23.5 & 23.5 \\
\hline & POCO AGRADABLE & 64 & 55.7 & 55.7 & 79.1 \\
\hline & AGRADABLE & 24 & 20.9 & 20.9 & 100.0 \\
\hline & Total & 115 & 100.0 & 100.0 & \\
\hline
\end{tabular}

\section{Análisis interpretativo}

Otra pregunta para conocer el grado de satisfacción/insatisfacción de los trabajadores sobre el liderazgo de sus superiores es si consideran que el jefe tiene la capacidad de generar un ambiente laboral agradable que sea óptimo para el buen desempeño de toda la organización. Como hemos podido apreciar en los cuadros anteriores sobre liderazgo, los resultados y gráficos son semejantes, siendo el 23.5\% que consideran nada agradable, $55.7 \%$ poco agradable y $20.9 \%$ agradable. Una vez 
más podemos apreciar el alto grado de nada/poco agradable con sus jefes $(79.2 \%)$, evidenciando una tendencia preocupante en la percepción de los trabajadores de sus jefes inmediatos.

\section{Pregunta 15}

Los esfuerzos de los jefes se encaminan al logro de objetivos de mi institución (INMP).

\section{Cuadro 15}

\begin{tabular}{|c|c|c|c|c|c|}
\hline & & Frecuencia & Porcentaje & $\begin{array}{c}\text { Porcentaje } \\
\text { válido }\end{array}$ & $\begin{array}{c}\text { Porcentaje } \\
\text { acumulado }\end{array}$ \\
\hline Válidos & NO SE ENCAMINAN & 29 & 25.2 & 25.2 & 25.2 \\
\hline & INDIFERENCIA & 62 & 53.9 & 53.9 & 79.1 \\
\hline & SE ENCAMINAN & 24 & 20.9 & 20.9 & 100.0 \\
\hline & Total & 115 & 100.0 & 100.0 & \\
\hline
\end{tabular}

\section{Análisis interpretativo}

Esta pregunta pretende determinar si las acciones de los jefes están encaminadas para alcanzar los objetivos de la organización. Así el 25.2\% manifiesta que no se encaminan los esfuerzos de los jefes, mientras que el $53.9 \%$ dicen que son indiferentes si se encaminan o no, y el $20.9 \%$ opina que los jefes sí encaminan al logro de los objetivos de la institución. Tales resultados evidencian una falta de capacidad de los jefes para manejar el grupo humano que tienen a cargo hacia el logro de objetivos organizacionales.

\section{Pregunta 16}

Mi jefe inmediato apoya mis esfuerzos.

Cuadro 16

\begin{tabular}{|c|c|c|c|c|c|}
\hline & & Frecuencia & Porcentaje & $\begin{array}{c}\text { Porcentaje } \\
\text { válido }\end{array}$ & $\begin{array}{c}\text { Porcentaje } \\
\text { acumulado }\end{array}$ \\
\hline Válidos & NO APOYA & 33 & 28.7 & 28.7 & 28.7 \\
\hline & INDISTINTO & 55 & 47.8 & 47.8 & 76.5 \\
\hline & APOYA & 27 & 23.5 & 23.5 & 100.0 \\
\hline & Total & 115 & 100.0 & 100.0 & \\
\hline
\end{tabular}

\section{Análisis interpretativo}

En cuanto a los resultados obtenidos sobre el nivel de apoyo de los jefes frente al empleado, podemos ver que resalta la opción indistinto que posee el $47.8 \%$, seguido por no apoya con $28.7 \%$ y apoya con el $23.5 \%$. Tales cifras indican una tendencia por cuanto los jefes no apoyan los esfuerzos de los trabajadores o son indiferentes de los logros de colaboradores.

\section{Pregunta 17}

Existe una buena comunicación entre mis compañeros de trabajo.
Cuadro 17

\begin{tabular}{|l|c|c|c|c|c|}
\hline & & Frecuencia & Porcentaje & $\begin{array}{c}\text { Porcentaje } \\
\text { valido }\end{array}$ & $\begin{array}{c}\text { Porcentaje } \\
\text { acumulado }\end{array}$ \\
\hline Válidos & NO EXISTE & 16 & 13.9 & 13.9 & 13.9 \\
\hline & INDIFERENTE & 63 & 54.8 & 54.8 & 68.7 \\
\hline & EXISTE & 36 & 31.3 & 31.3 & 100.0 \\
\hline & Total & 115 & 100.0 & 100.0 & \\
\hline
\end{tabular}

\section{Análisis interpretativo}

Los resultados sobre si existe una buena comunicación entre compañeros de trabajo los encuestados manifiestan en su mayoría (54.8\%) que es indiferente, seguido del $31.3 \%$ que dicen existe una buena comunicación y el $13.9 \%$ que manifiesta que no existe una buena comunicación. De tales resultados podemos colegir que en su mayor porcentaje los trabajadores del Instituto Nacional Materno Perinatal opinan no existe una buena comunicación de los directivos hacia los trabajadores o en su defecto son indiferentes.

\section{Pregunta 18}

Las reuniones de coordinación con los miembros de otras áreas son frecuentes.

\section{Cuadro 18}

\begin{tabular}{|c|c|c|c|c|c|}
\hline & & Frecuencia & Porcentaje & $\begin{array}{c}\text { Porcentaje } \\
\text { válido }\end{array}$ & $\begin{array}{c}\text { Porcentaje } \\
\text { acumulado }\end{array}$ \\
\hline Válidos & MALO & 39 & 33.9 & 33.9 & 33.9 \\
\hline & REGULAR & 51 & 44.3 & 44.3 & 78.3 \\
\hline & BUENO & 25 & 21.7 & 21.7 & 100.0 \\
\hline & Total & 115 & 100.0 & 100.0 & \\
\hline
\end{tabular}

\section{Análisis interpretativo}

En la pregunta para ver la frecuencia de las reuniones de coordinación con los miembros de otras áreas podemos ver que regular tiene mayor porcentaje con $44.3 \%$, seguido de malo $33.9 \%$ y al final bueno con $21.7 \%$. Se desprende que los encuestados consideran la falta de coordinación con otras áreas como una falencia importante.

\section{Pregunta 19}

Presto atención a los comunicados que emiten mis jefes.

Cuadro 19

\begin{tabular}{|c|c|c|c|c|c|}
\hline & & Frecuencia & Porcentaje & $\begin{array}{c}\text { Porcentaje } \\
\text { válido }\end{array}$ & $\begin{array}{c}\text { Porcentaje } \\
\text { acumulado }\end{array}$ \\
\hline Válidos & MALO & 26 & 22.6 & 22.6 & 22.6 \\
\hline & REGULAR & 47 & 40.9 & 40.9 & 63.5 \\
\hline & BUENO & 42 & 36.5 & 36.5 & 100.0 \\
\hline & Total & 115 & 100.0 & 100.0 & \\
\hline
\end{tabular}




\section{Análisis interpretativo}

Frente a la pregunta realizada "Presto atención a los comunicados que emiten mis jefes" podemos ver que la respuesta regular va primero con $40.9 \%$, seguido de bueno $36.5 \%$ y al final malo con $22.6 \%$, con lo cual los encuestados nos muestran su falta de atención a las disposiciones de sus superiores. Es alarmante el $22.6 \%$ de malo ya que demuestra la falta de interés frente a las órdenes de los superiores.

\section{Pregunta 20}

Mi organización de salud se encuentra organizada para prever los problemas que se presentan.

\section{Cuadro 20}

\begin{tabular}{|c|c|c|c|c|c|}
\hline & & Frecuencia & Porcentaje & $\begin{array}{c}\text { Porcentaje } \\
\text { válido }\end{array}$ & $\begin{array}{c}\text { Porcentaje } \\
\text { acumulado }\end{array}$ \\
\hline Válidos & NO ORGANIZADA & 28 & 24.3 & 24.3 & 24.3 \\
\hline & INDIFERENTE & 59 & 51.3 & 51.3 & 75.7 \\
\hline & ORGANIZADA & 28 & 24.3 & 24.3 & 100.0 \\
\hline & Total & 115 & 100.0 & 100.0 & \\
\hline
\end{tabular}

\section{Análisis interpretativo}

En este cuadro se evalúa la capacidad de la organización para hacer frente a las distintas situaciones que se puedan dar y deba enfrentar la organización y obtuvimos respuestas dispares; así el $24.3 \%$ opina que la institución se encuentra organizada, el $51.3 \%$ manifiesta que es indiferente si se encuentra organizada o no, y el $24.3 \%$ opina que el INMP no se encuentra organizado. Esta tendencia es preocupante si se tiene en cuenta que el $75.6 \%$ de los encuestados se manifiestan en contrario a las aspiraciones del Instituto Nacional Materno Perinatal.

\section{Pregunta 21}

El trabajo que realizo permite que desarrolle al máximo todas mis capacidades.

\section{Cuadro 21}

\begin{tabular}{|c|l|c|c|c|c|}
\hline & & Frecuencia & Porcentaje & $\begin{array}{c}\text { Porcentaje } \\
\text { valido }\end{array}$ & $\begin{array}{c}\text { Porcentaje } \\
\text { acumulado }\end{array}$ \\
\hline Válidos & MINIMO & 25 & 21.7 & 21.7 & 21.7 \\
\hline & INDISTINTO & 54 & 47.0 & 47.0 & 68.7 \\
\hline & MAXIMO & 36 & 31.3 & 31.3 & 100.0 \\
\hline & Total & 115 & 100.0 & 100.0 & \\
\hline
\end{tabular}

\section{Análisis interpretativo}

Otra pregunta referida a la satisfacción o insatisfacción que puede haber con respecto al puesto de trabajo, está referida al desarrollo de las capacidades de los colaboradores. La opinión de los encuestados se encuentra concentrado en indistinto donde el $47 \%$ manifiesta que es indistinto, en tanto que el $31.3 \%$ opina que sí le permite desarrollar al máximo sus capacidades. De la misma forma el $21.7 \%$ dicen que el trabajo que realiza le permiten al mínimo sus capacidades.

\section{Pregunta 22}

Mi institución es flexible y se adapta bien a los cambios.

Cuadro 22

\begin{tabular}{|c|c|c|c|c|c|}
\hline & & Frecuencia & Porcentaje & $\begin{array}{c}\text { Porcentaje } \\
\text { válido }\end{array}$ & $\begin{array}{c}\text { Porcentaje } \\
\text { acumulado }\end{array}$ \\
\hline Válidos & INFLEXIBLE & 30 & 26.1 & 26.1 & 26.1 \\
\hline & INDIFERENTE & 60 & 52.2 & 52.2 & 78.3 \\
\hline & FLEXIBLE & 25 & 21.7 & 21.7 & 100.0 \\
\hline & Total & 115 & 100.0 & 100.0 & \\
\hline
\end{tabular}

\section{Análisis interpretativo}

Aquí se analizará la percepción que tienen los colaboradores del INMP con respecto a la capacidad que tiene la institución en cuanto a la flexibilidad y a su poder de adaptación a los cambios. Consideran que la capacidad del INMP de adaptarse al cambio es en su mayoría indiferente con un $52.2 \%$ e inflexible con un $26.1 \%$. Esto se puede explicar por los conflictos que viene presentando la institución por las huelgas y reclamos pendientes por los trabajadores del INMP. En ese orden de ideas solo $21.7 \%$ respondió que el INMP es flexible para adaptarse a los cambios.

\section{Pregunta 23}

Estoy comprometido con mi organización (INMP).

Cuadro 23

\begin{tabular}{|c|l|c|c|c|c|}
\hline & & Frecuencia & Porcentaje & $\begin{array}{c}\text { Porcentaje } \\
\text { válido }\end{array}$ & $\begin{array}{c}\text { Porcentaje } \\
\text { acumulado }\end{array}$ \\
\hline Válidos & NO COMPROMETIDO & 21 & 18.3 & 18.3 & 18.3 \\
\hline & INDIFERENTE & 32 & 27.8 & 27.8 & 46.1 \\
\hline & COMPROMETIDO & 62 & 53.9 & 53.9 & 100.0 \\
\hline & Total & 115 & 100.0 & 100.0 & \\
\hline
\end{tabular}

\section{Análisis interpretativo}

En este cuadro los encuestados califican que se encuentran altamente comprometidos con el correcto desempeño de la institución, buscando brindar un servicio de calidad y de atención al cliente adecuada. Es así que el $53.9 \%$ se encuentra comprometido, con el cumplimiento de las normas establecidas y existe una identificación con 
la organización, mientras que el $27.8 \%$ considera este compromiso como indiferente y tan solo el $18.3 \%$ respondió que no existía un compromiso.

\section{Pregunta 24}

¿Cuál de las siguientes categorías describe mejor su puesto de trabajo dentro de la organización?

Cuadro 24

\begin{tabular}{|c|c|c|c|c|c|}
\hline & & Frecuencia & Porcentaje & $\begin{array}{c}\text { Porcentaje } \\
\text { válido }\end{array}$ & $\begin{array}{l}\text { Porcentaje } \\
\text { acumulado }\end{array}$ \\
\hline \multirow[t]{10}{*}{ Válidos } & Director & 5 & 4.3 & 4.3 & 4.3 \\
\hline & Funcionario & 10 & 8.7 & 8.7 & 13.0 \\
\hline & Jefe de Departamento & 3 & 2.6 & 2.6 & 15.7 \\
\hline & Jefe de Servicio & 12 & 10.4 & 10.4 & 26.1 \\
\hline & Jefe de Establecimiento & 5 & 4.3 & 4.3 & 30.4 \\
\hline & Personal Administrativo & 42 & 36.5 & 36.5 & 67.0 \\
\hline & Personal Asistencial & 16 & 13.9 & 13.9 & 80.9 \\
\hline & Personal de Servicio & 17 & 14.8 & 14.8 & 95.7 \\
\hline & Otros & 5 & 4.3 & 4.3 & 100.0 \\
\hline & Total & 115 & 100.0 & 100.0 & \\
\hline
\end{tabular}

\section{Análisis interpretativo}

El presente cuadro revela la distribución de los trabajadores de acuerdo al área en la cual laboran, que van desde el desempeño de actividades asistenciales hasta las actividades netamente administrativas. En la muestra la mayoría de los encuestados fueron del área administrativa, ya que ellos disponen en cierta medida de un mayor tiempo y disponibilidad al llenado de una encuesta, mientras que los colaboradores que desempeñan actividades asistenciales se ven restringidos a colaborar debido a estar constantemente en el desarrollo de sus funciones para el correcto desempeño de la institución.

\section{Pregunta 25}

¿A qué grupo ocupacional pertenece?

Cuadro 25

\begin{tabular}{|c|c|c|c|c|c|}
\hline & & Frecuencia & Porcentaje & $\begin{array}{c}\text { Porcentaje } \\
\text { válido }\end{array}$ & $\begin{array}{l}\text { Porcentaje } \\
\text { acumulado }\end{array}$ \\
\hline \multirow[t]{10}{*}{ Válidos } & Médico & 10 & 8.7 & 8.7 & 8.7 \\
\hline & Enfermera & 14 & 12.2 & 12.2 & 20.9 \\
\hline & Obstetra & 12 & 10.4 & 10.4 & 31.3 \\
\hline & Odontólogo & 1 & 0.9 & 0.9 & 32.2 \\
\hline & Nutricionista & 7 & 6.1 & 6.1 & 38.3 \\
\hline & Trabajadora Social & 7 & 6.1 & 6.1 & 44.3 \\
\hline & Técnico de Enfermería & 21 & 18.3 & 18.3 & 62.6 \\
\hline & Técnico Administrativo & 28 & 24.3 & 24.3 & 87.0 \\
\hline & Otros & 15 & 13.0 & 13.0 & 100.0 \\
\hline & Total & 115 & 100.0 & 100.0 & \\
\hline
\end{tabular}

\section{Análisis interpretativo}

El presente cuadro revela la clasificación de los colaboradores de acuerdo a su formación profesional. Vemos que existe un alto número de técnicos administrativos debido a lo expuesto puntos antes, debido a la disponibilidad de tiempo de los trabajadores cuyas funciones son asistenciales. Y también se observa un mayor número en cuanto a las enfermeras, médicos obstetras y técnicos de enfermería, esto estaría acorde ya que estos son los encargados de velar por los beneficiarios.

\section{Pregunta 26}

¿Cuál es su condición laboral en el INMP?

Cuadro 26

\begin{tabular}{|c|c|c|c|c|c|}
\hline & & Frecuencia & Porcentaje & $\begin{array}{c}\text { Porcentaje } \\
\text { válido }\end{array}$ & $\begin{array}{c}\text { Porcentaje } \\
\text { acumulado }\end{array}$ \\
\hline Válidos & Nombrado & 71 & 61.7 & 61.7 & 61.7 \\
\hline & Contratado a plazo fijo & 18 & 15.7 & 15.7 & 77.4 \\
\hline & Locación de Servicios & 8 & 7.0 & 7.0 & 84.3 \\
\hline & Service & 4 & 3.5 & 3.5 & 87.8 \\
\hline & Otros & 14 & 12.2 & 12.2 & 100.0 \\
\hline & Total & 115 & 100.0 & 100.0 & \\
\hline
\end{tabular}

\section{Análisis interpretativo}

El presente cuadro nos indica la condición laboral en la que se encuentran en la actualidad en el INMP. Como se puede ver la gran mayoría, incluso más del $50 \%$ de encuestados dijo pertenecer al grupo de los nombrados se aprecia eso con un $61.7 \%$, el segundo grupo con mayor número de individuos es el de contratados a plazo fijo con un $15.7 \%$ y el grupo de otros es de $12.2 \%$. En este punto se tuvo problemas en cuanto a determinar su condición laboral ya que muchos de ellos no sabían el tipo de contrato que tenían con la institución.

\section{Pregunta 27}

¿Cuál es su tiempo de servicios en el INMP?

Cuadro 27

\begin{tabular}{|c|c|c|c|c|c|}
\hline & & Frecuencia & Porcentaje & $\begin{array}{c}\text { Porcentaje } \\
\text { válido }\end{array}$ & $\begin{array}{c}\text { Porcentaje } \\
\text { acumulado }\end{array}$ \\
\hline Válidos & Menos de 1 año & 21 & 18.3 & 18.3 & 18.3 \\
\hline & De 1 a 4 años & 38 & 33.0 & 33.0 & 51.3 \\
\hline & De 5 años a más & 56 & 48.7 & 48.7 & 100.0 \\
\hline & Total & 115 & 100.0 & 100.0 & \\
\hline
\end{tabular}

\section{Análisis interpretativo}

En este cuadro mostramos los años laborados por parte de los trabajadores en la institución, la cual está relacionada con el tipo de condición laboral a la cual se encuentran sujetos. Vemos 
que tanto el punto de 1 a 4 años y de 5 años a más tienen $33 \%$ y $48.7 \%$, respectivamente, lo que representaría a los trabajadores en condición de nombrados y contratados a plazo fijo. Y el punto de menos de 1 año se puede deber a la tercerización que se realiza en la institución con la finalidad quizás de bajar los costos y reducir el pago de beneficios a los trabajadores si estos fueran nombrados o con contrato a plazo fijo.

\section{COMPROBACIÓN DE HIPÓTESIS CRUZANDO VARIABLES}

\section{Hipótesis a}

- H0: El liderazgo y conocimiento de los jefes no genera un mayor nivel de satisfacción en los colaboradores del Instituto Nacional Materno Perinatal.

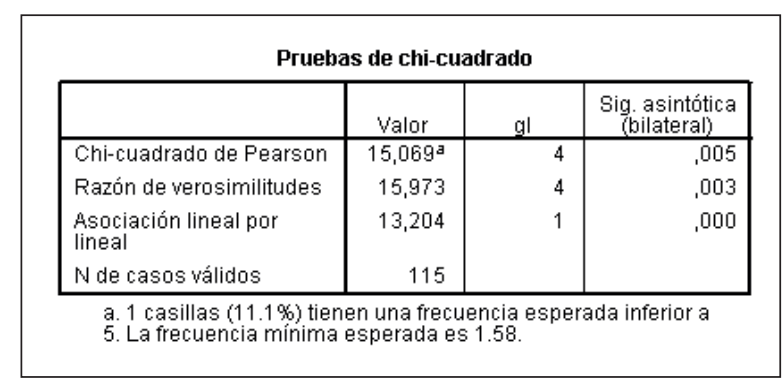

Como podemos apreciar en la tabla de pruebas de chi-cuadrado, el valor experimental de chicuadrado es 19.580 , siendo este valor superior al valor tabular lo que le permite que la hipótesis nula sea rechazada a un nivel de significancia del $5 \%$ por lo que se concluye que el liderazgo y conocimiento de los jefes sí genera un mayor nivel de satisfacción en los colaboradores del Instituto Nacional Materno Perinatal.

\begin{tabular}{|c|c|c|c|c|c|c|}
\hline \multicolumn{7}{|c|}{$\begin{array}{c}\text { Tabla de contingencia: La institución se preocupa por las necesidades primordiales del personal. * Existen incentivos } \\
\text { laborales para que yo trate de hacer mejor mi trabajo. }\end{array}$} \\
\hline & & & \multicolumn{3}{|c|}{$\begin{array}{c}\text { Existen incentivos laborales para que yo trate de } \\
\text { hacer mejor mi trabajo. }\end{array}$} & \multirow[b]{2}{*}{ Total } \\
\hline & & & MALO & REGULAR & BUENO & \\
\hline \multirow{6}{*}{$\begin{array}{l}\text { La institución se } \\
\text { preocupa por las } \\
\text { necesidades } \\
\text { primordiales del } \\
\text { personal. }\end{array}$} & \multirow[t]{2}{*}{ MALO } & Recuento & 29 & 15 & 3 & $4 ?$ \\
\hline & & Frecuencia esperada & 22,1 & 19,2 & 5,7 & 47,0 \\
\hline & \multirow[t]{2}{*}{ REGULAR } & Recuento & 20 & 25 & 7 & 52 \\
\hline & & Frecuencia esperada & 24,4 & 21,3 & 6,3 & 52,0 \\
\hline & \multirow[t]{2}{*}{ BUENO } & Recuento & 5 & 7 & 4 & 16 \\
\hline & & Frecuencia esperada & 3,5 & 6,5 & 1,9 & 16,0 \\
\hline \multirow[t]{2}{*}{ Total } & & Recuento & 54 & 47 & 14 & 115 \\
\hline & & Frecuencia esperada & 54,0 & 43,0 & 14,0 & 115,0 \\
\hline
\end{tabular}

- H1: El liderazgo y conocimiento de los jefes sí genera un mayor nivel de satisfacción en los colaboradores del Instituto Nacional Materno Perinatal.

Los datos han sido clasificados en una tabla de contingencia para probar la hipótesis de independencia. Se ha considerado un nivel de significancia $\alpha=0.05$ y un grado de libertad de 4 (3-1) $\times(3-1)$ $=2 \times 2=4$, cuyo valor tabular es de $X^{2}=9.488$, que luego será comprobado con un chi-cuadrado experimental para la aceptación o rechazo de la hipótesis nula.

Cálculo del chi-cuadrado experimental:

$$
\chi^{2}=\sum \frac{\left(o_{\bar{i}}-e_{i}\right)^{2}}{e_{i}}
$$

\section{Hipótesis b}

- H0: No es importante una adecuada comunicación entre colaboradores y con sus jefes para que estén comprometidos con el desarrollo del Instituto Nacional Materno Perinatal.

- H1: Sí es importante una adecuada comunicación entre colaboradores y con sus jefes para que estén comprometidos con el desarrollo del Instituto Nacional Materno Perinatal.

Los datos han sido clasificados en una tabla de contingencia para probar la hipótesis de independencia. Se ha considerado un nivel de significancia $\alpha=0.05$ y un grado de libertad de $4(3-1) \times(3-1)$ $=2 \times 2=4$, cuyo valor tabular es de $\mathrm{X}^{2}=9.488$, que luego será comprobado con un chi-cuadrado experimental para la aceptación o rechazo de la hipótesis nula. 
Cálculo del chi-cuadrado experimental:

$$
\chi^{2}=\sum \frac{\left(o_{i}-e_{i}\right)^{2}}{e_{i}}
$$

\begin{tabular}{|c|c|c|c|c|c|c|}
\hline \multicolumn{7}{|c|}{$\begin{array}{l}\text { Tabla de contingencia: Los directivos del centro laboral hacen los esfuerzos necesarios para mantener informados } \\
\text { oportunamente a los trabajadores sobre los asuntos que nos afectan e interesan, así como del rumbo de la institución. * } \\
\text { Existe una buena comunicación entre mis compañeros de trabajo. }\end{array}$} \\
\hline & & & \multicolumn{3}{|c|}{$\begin{array}{c}\text { Existe una buena comunicación entre mis } \\
\text { compañeros de trabajo. }\end{array}$} & \multirow[b]{2}{*}{ Total } \\
\hline & & & MALO & REGULAR & BUENO & \\
\hline \multirow{6}{*}{$\begin{array}{l}\text { Los directivos del centro } \\
\text { laboral hacen los } \\
\text { esfuerzos necesarios } \\
\text { para mantener } \\
\text { informados } \\
\text { oportunamente a los } \\
\text { trabajadores sobre los } \\
\text { asuntos que nos afectan } \\
\text { e interesan, así como del } \\
\text { rumbo de la institución. }\end{array}$} & \multirow[t]{2}{*}{ MALO } & Recuento & 3 & 21 & 8 & 32 \\
\hline & & Frecuencia esperada & 4,5 & 17,5 & 10,0 & 32,0 \\
\hline & \multirow[t]{2}{*}{ REGULAR } & Recuento & 10 & 31 & 20 & 61 \\
\hline & & Frecuencia esperada & 8,5 & 33,4 & 19,1 & 61,0 \\
\hline & \multirow[t]{2}{*}{ BUENO } & Recuento & 3 & 11 & 8 & 22 \\
\hline & & Frecuencia esperada & 3,1 & 12,1 & 6,9 & 22,0 \\
\hline \multirow[t]{2}{*}{ Total } & & Recuento & 16 & 63 & 36 & 115 \\
\hline & & Frecuencia esperada & 16,0 & 63,0 & 36,0 & 115,0 \\
\hline
\end{tabular}

\begin{tabular}{|ll|r|r|r|r||}
\hline \multicolumn{8}{|c|}{ Tabla de contingencia: Los directivosy jefes demuestran un dominio técnicoy conocimientos de sus funciones. * Mi jefe } \\
inmediato se preocupa por crear un ambiente laboral agradable.
\end{tabular}

Como podemos apreciar en la tabla de pruebas de chi-cuadrado, el valor experimental de chicuadrado es 2.327 , siendo este valor inferior al valor tabular lo que le permite que la hipótesis alterna sea rechazada a un nivel de significancia del $5 \%$ por lo que se concluye que no es importante una adecuada comunicación entre colaboradores y con sus jefes para que estén comprometidos con el desarrollo del Instituto Nacional Materno Perinatal.

\section{Hipótesis c}

- H0: Los incentivos que ofrece el Instituto Nacional Materno Perinatal no aumenta la productividad de los colaboradores ni genera un clima laboral adecuado.

- H1: Los incentivos que ofrece el Instituto Nacional Materno Perinatal sí aumenta la productividad de los colaboradores y genera un clima laboral adecuado.

Los datos han sido clasificados en una tabla de contingencia para probar la hipótesis de independencia. Se ha considerado un nivel de significancia $\alpha=0.05$ y un grado de libertad de 4 (3-1) x (3-1) $=2 \times 2=4$, cuyo valor tabular es de $X^{2}=9.488$, que luego será comprobado con un chi-cuadrado experimental para la aceptación o rechazo de la hipótesis nula. 
Cálculo del chi-cuadrado experimental:

$$
\chi^{2}=\sum \frac{\left(o_{i}-e_{i}\right)^{2}}{e_{i}}
$$

Como podemos apreciar en la tabla de pruebas de chi-cuadrado, el valor experimental de chicuadrado es 15.069 , siendo este valor superior al valor tabular lo que le permite que la hipótesis nula sea rechazada a un nivel de significancia del $5 \%$ por lo que se concluye que los incentivos que ofrece el Instituto Nacional Materno Perinatal sí aumentan la productividad de los colaboradores y generan un clima laboral adecuado.

\section{Hipótesis d}

- H0: La reciprocidad entre los trabajadores y el Instituto Nacional Materno Perinatal no influye en la satisfacción laboral.

- H1: La reciprocidad entre los trabajadores y el Instituto Nacional Materno Perinatal sí influye en la satisfacción laboral.
Los datos han sido clasificados en una tabla de contingencia para probar la hipótesis de independencia. Se ha considerado un nivel de significancia $\alpha=0.05$ y un grado de libertad de 4 (3-1) x (3-1) $=2 \times 2=4$, cuyo valor tabular es de $\mathrm{X}^{2}=9.488$, que luego será comprobado con un chi-cuadrado experimental para la aceptación o rechazo de la hipótesis nula.

Cálculo del chi-cuadrado experimental:

$$
\chi^{2}=\sum \frac{\left(o_{i}-e_{i}\right)^{2}}{e_{i}}
$$

Como podemos apreciar en la tabla de pruebas de chi-cuadrado, el valor experimental de chicuadrado es 14.399 , siendo este valor superior al valor tabular lo que le permite que la hipótesis nula sea rechazada a un nivel de significancia del $5 \%$, por lo que se concluye que la reciprocidad entre los trabajadores y el Instituto Nacional Ma-

\begin{tabular}{|c|c|c|c|c|c|c|}
\hline \multicolumn{7}{|c|}{ Tabla de contingencia } \\
\hline & & & \multicolumn{3}{|c|}{$\begin{array}{c}\text { Estoy comprometido con mi organización de } \\
\text { salud. }\end{array}$} & \multirow[b]{2}{*}{ Total } \\
\hline & & & MALO & REGULAR & BUENO & \\
\hline \multirow{6}{*}{$\begin{array}{l}\text { En términos generales } \\
\text { me siento satisfecho con } \\
\text { mi centro laboral. }\end{array}$} & MALO & Recuento & 8 & 8 & 5 & 21 \\
\hline & & Frecuencia esperada & 3,8 & 5,8 & 11,3 & 21,0 \\
\hline & REGULAR & Recuento & 6 & 19 & 36 & 61 \\
\hline & & Frecuencia esperada & 11,1 & 13,0 & 32,9 & 61,0 \\
\hline & BUENO & Recuento & 7 & 5 & 21 & 33 \\
\hline & & Frecuencia esperada & 6,0 & 9,2 & 17,8 & 33,0 \\
\hline \multirow[t]{2}{*}{ Total } & & Recuento & 21 & 32 & 62 & 115 \\
\hline & & Frecuencia esperada & 21,0 & 32,0 & 62,0 & 115,0 \\
\hline
\end{tabular}
terno Perinatal sí influye en la satisfacción laboral.

Pruebas de chi-cuadrado

\begin{tabular}{|l|r|r|r|}
\hline & \multicolumn{1}{|c|}{ Valor } & gl & \multicolumn{1}{c|}{$\begin{array}{c}\text { ig. asintótica } \\
\text { (bilateral) }\end{array}$} \\
\hline Chi-cuadrado de Pearson & $14,399^{\mathrm{a}}$ & 4 &, 006 \\
Razón de verosimilitudes & 14,973 & 4 &, 005 \\
Asociación lineal por & 5,115 & 1 &, 024 \\
lineal & 115 & & \\
N de casos válidos & & & \\
\hline
\end{tabular}

a. 1 casillas $(11.1 \%)$ tienen una frecuencia esperada inferior a 5. La frecuencia mínima esperada es 3.83 . 


\section{CONCLUSIONES}

Después de haber realizado el trabajo de investigación y alcanzado los objetivos planteados, las siguientes son las conclusiones a las cuales hemos arribado:

1. Una alta capacidad de liderazgo por parte de los jefes o directivos sí es importante para dirigir la organización. Los encuestados consideran que sus jefes deben de tener la capacidad técnica y de conocimiento para ejercer sus funciones, resaltando que el jefe debe crear un ambiente agradable, propiciando el desarrollo de los trabajadores, dándoles confianza y delegandole las funciones, así como tener la capacidad de solucionar los problemas que se puedan ir presentando en cada área de trabajo.

2. Podemos decir que desde la perspectiva de los trabajadores del Instituto Nacional Materno Perinatal, la comunicación entre colaboradores y jefes no es determinante para que estén comprometidos con el desarrollo de la institución, ya que ellos consideran que se encuentran muy comprometidos a pesar las deficiencias que puedan existir en los canales de comunicación dentro de la organización al considerar que muchas veces no son informados sobre su desempeño ni respecto a asuntos que les afectan e interesan.

3. Se puede aseverar que la motivación sí es un factor determinante para la satisfacción en el trabajo por parte de los encuestados. De acuerdo a los colaboradores no existe una buena retribución ni reconocimiento por parte del Instituto; consideran que no existe una adecuada valoración a su trabajo, que no les permite cubrir con sus principales necesidades básicas. Los empleados no sienten ser valorados dado que la organización no les da oportunidad de capacitarse y poder desarrollar sus capacidades en beneficio del cumplimiento de sus labores ni de su desarrollo personal.

4. Entonces se puede afirmar que si existe una retribución adecuada entre la organización y el trabajador se puede generar un ambiente de satisfacción laboral. Los encuestados consideran que no se encuentran del todo satisfechos con su centro laboral pero que sí están interesados en el desarrollo de la Institución, siendo gratificante trabajar en el INMP. Esta insatisfacción existente en los trabajadores muchas veces se debe a que no existe una ade- cuada distribución de los recursos necesarios, herramientas e instrumentos que los ayude a tener un buen desempeño.

\section{RECOMENDACIONES}

1. Es necesario que el Instituto Nacional Materno Perinatal realice un seguimiento de cómo los jefes realizan sus funciones, a la vez que se realizan evaluaciones de sus capacidades y conocimientos que son necesarios para desempeñarse óptimamente. Estas medidas se deben a que la gran mayoría no está conforme con el desempeño de sus jefes inmediatos. Esta situación puede conllevar a un mayor número de conflictos internos como también a un mal desempeño de la Institución.

2. Como ya sabemos que la comunicación no es determinante para generar un óptimo clima laboral y un nivel de satisfacción laboral aceptable, sería recomendable no preocuparse mucho en este aspecto sino en otros aspectos que sí adolece; por ejemplo, en la motivación a sus colaboradores, el sentimiento de reciprocidad institución-colaboradores y los problemas de liderazgo de sus jefes.

3. Tener en cuenta aumentar el presupuesto para ofrecer mayores oportunidades de capacitación, ofrecer un pago justo por la labor realizada de los colaboradores, entre otros mecanismos de motivación. Esto es necesario porque gran parte del personal está desmotivado ya que consideran que la institución no reconoce ni valora su esfuerzo y eso se traduce en una escasez de oportunidades para desarrollarse como personas como también para tener una vida digna sin preocupaciones económicas.

4. Como hemos podido ver existe un alto nivel de reciprocidad de trabajador. El Instituto Nacional Materno Perinatal puede solucionar esta situación con una mayor cantidad de oportunidades de capacitación, una justa remuneración económica, una adecuada distribución de los recursos y herramientas necesarios para tener un buen desempeño en su trabajo.

\section{REFERENCIAS BIBLIOGRÁFICAS}

Astudillo, C. (1985). Cuestionario para medir clima organizacional en instituciones financieras. Tesis para optar al título de Psicólogo. Santiago de Chile. 
Escuela de Psicología, Pontificia Universidad Católica de Chile.

Bravo, M.J, Peiró, J.M y Rodríguez, I. (1996). Satisfacción laboral. En: J. Peiró y F. Prieto (Eds.). Tratado de psicología del trabajo, 1. La actividad laboral en su contexto. España: Ed. Síntesis S.A. 343-394.

Brunet Luc. (2007). El clima de trabajo en las organizaciones: Definición, diagnóstico y consecuencias. México D.F. Editorial Trillas.

Bustos, Paulina y Miranda, Mauricio. (2001). Clima Organizacional. Santiago de Chile: Editorial Lautaro.

Campbell J, Dunnette M, Lawler E. y Weick K. (1970). Managerial behaviour, performance and effectiveness. New York: McGraw-Hill.

Chiavenato, Idalberto. (2000). Administración de Recursos Humanos. Bogotá: Editorial Presencia.

Davis, Keith; Newstrom, John. (1993). Comportamiento Humano en el Trabajo. Comportamiento Organizacional. México D.F.: McGraw Hill.

Hackett, R. D., y Guion, R. M. (1985). A re-evaluation of the absenteeism-job satisfaction relationship.Organizational Behavior and Human Decision Processes, 35, pp. 340-381.

Herzberg, F., Mausner, B. y Snyderman, B. (1959). The Motivation to Work. New York: Wiley.

Hodgetts, R y Altman, S. 1985. Comportamiento en las organizaciones. (6ta ed). Mexico DF. Interamericana editores.

Hulin, C.L. (1991). Adaptation, persistence, and commitment in organizations. In M.D. Dunnette \& L.M. Hough (Eds.), Handbook of industrial and organizational psychology (2nd ed., Vol. 2, pp. 445-505). Palo Alto, CA: Consulting Psychologist Press.

Hunt James y John Schermerhorn. (2004). Comportamiento Organizacional. México D.F.: Limusa Wiley, p.278

Justiniano, O. (1984). Cuestionario para medir clima organizacional en instituciones educacionales. Tesis para optar al título de Psicólogo. Santiago de Chile. Escuela de Psicología, Pontificia Universidad Católica de Chile.

Katz, Daniel - Kahn, Robert L. (2005). Psicología Social de las Organizaciones. Editorial Trillas.
Lewin, K. (1939).Teoría del campo y experimentación en psicología social, Cuaderno $\mathrm{N}^{\mathrm{O}}$ 10 del Instituto de Sociología de la Fac. de Filosofía de la UBA, 195

Likert, R. (1961). New Patterns of Management. New York: McGraw Hill.

Litwin, G. \& Stringer, R. (1968). Motivation and Organizational Climate. Boston: Harvard Business School Press.

Lotito, F. (1992). Relación entre la percepción de clima organizacional y algunas características de personalidad: un estudio exploratorio. Tesis para optar al título de Psicólogo. Santiago de Chile. Escuela de Psicología, Pontificia Universidad Católica de Chile.

Marchant, L. (2005). Actualizaciones para el Desarrollo Organizacional. Primer Seminario Viña del Mar, Chile.

Marchant, Loreto. (2003). Estudio descriptivo de la influencia del clima organizacional sobre el comportamiento de las personas en empresas de la quinta región. Tesis de post grado. Escuela de graduados. Facultad de Ciencias económicas y Administrativas Universidad de Valparaíso. Chile

Martínez, L. (2001). Clima organizacional. [On line]. Disponible: http://www.monografias. com/trabajos6/clior/clior.shtml

Ministerio de Salud (2004). Factores de clima organizacional influyentes en la satisfacción laboral de enfermería, concernientes a los cuidados intensivos neonatales del Hospital Nacional de Niños.

Ministerio de Salud (2010). Metodología para el estudio de clima organizacional Ministerio de Salud del Perú. Dirección General de Salud de las personas Dirección de Calidad en Salud RM N623-2008/MINSA.

Muchinsky, Paul (1994). Psicología Aplicada al Trabajo: Introducción a la Psicología Industrial y Organizacional. Bilbao. Ed. Desclée de Brouwer, S.A.

Peiró, J. y Prieto, F. (1996). Tratado de Psicología del Trabajo. Aspectos psicosociales del trabajo. Madrid: Editorial Síntesis psicológica.

Pelaez, Oswaldo (2010). Relación entre el clima organizacional y la satisfacción del cliente en una empresa de servicios telefónicos. Tesis de doctorado. Lima. 
Perez, J. Villalva, M. (2002). Diccionario de Administración y Finanzas. España. Grupo editorial Oceano SA.

Reichers, A. E. y Schneider,B. (1990). Climate and culture: An evolution of constructs. In B. Schneirder (Ed.), Organizational Climate and Culture, 5-39. San Francisco: Jossey - Bass.

Robbins, S y Coulter, M. (2000). Administración. (6ta ed). México D.F.: Pearson educación.

Robbins, S y De Cenzo, D. (2000). Fundamentos de Administración. (6ta ed). México D.F.: Pearson educación.

Rodríguez, D. (1992). Diagnóstico de clima organizacional. Santiago de Chile: Ediciones Pontificia Universidad Católica de Chile.

Rousseau, D. M. (1988). The Construction of Climate in Organizational Research. En C.I. Cooper y I. Robertson, International Review of Industrial and Organizationat Psychology.Wiley, 139-158.

Schneider, B. Snyder, R. A. (1975). Some relationships between job satisfaction and organizational climate. Journal of applied psychology, 60, Pág. 318-319.
Silva, M. (1992). El Clima en las Organizaciones. Teoría, método e intervención. Barcelona: PPU.

Tito, Pedro. (2007). El potencial humano y los estímulos organizacionales. Tesis de Maestria. Disponible en: file://C:/ Users/Basamet/Downloads/Tesis\%20de\%20 Maestr\%C3\%ADa\%20PEDRO\%20TITO\%20 HUAMANI\%20(1).pdf

Universidad Nacional de Colombia (2012). Clima Organizacional: elemento clave para el proceso de calidad en las instituciones prestadoras de la salud. Universidad Nacional de Colombia. Facultad de medicina programa especialización en administración de salud pública Bogotá.

Valle, R. (1995). Gestión Estratégica de Recursos Humanos. Addison Wesley Iberoamericana. Estados Unidos.

Vroom, V. H. (1964). Work and motivation. San Francisco, CA: Jossey-Bass.

Werther, y Davis. (1995). Administración de personal y Recursos Humanos. (4ta ed). México D.F.: Edit Mc Graw Hill. 